\title{
ПРОТИВОРЕЧИЕ РУССКОГО МОЛЧАНИЯ С ТОЧКИ ЗРЕНИЯ МЕЖКУЛЬТУРНОЙ КОММУНИКАЦИИ
}

\section{CONTRADICTION TO THE RUSSIAN SILENCE FROM THE POINT OF VIEW OF INTERCULTURAL COMMUNICATION \\ Tang Jiamin}

Summary: The article examines silence as an important part of nonverbal communication, as a state of silence, lack of dialogue and conversation. Attention is drawn to the fact that silence in Russian culture is a contradictory phenomenon, which is reflected in literary, film and television works, and this contradiction comes from values, the system of which was deeply influenced by Eastern and Western cultures, traditional Orthodox beliefs, unique humanistic and natural Wednesday. It is concluded that, within the framework of intercultural communication, while in a situation of silence, to understand the contradictions in the Russian national character, to respect the differences, which will contribute to full communication between representatives of different cultures.

Keywords: silence, non-verbal communication, culture, Russian literature, intercultural communication.

\author{
Тан Цзяминь \\ аспирант, Институт иностранных языков \\ Ланьчжоуского университета (КНР) \\ tangjm2020@/zu.edu.cn
}

Аннотация: В статье рассмотрено молчание как важная часть невербального общения, как состояние безмолвия, отсутствие диалога и разговора. Обращено внимание на то, что молчание в русской культуре является противоречивым явлением, что отражено в литературных, кино- и телевизионных произведениях, и это противоречие исходит из ценностей, на систему которых глубоко повлияли восточная и западная культуры, традиционные православные верования, уникальная гуманистическая и природная среда. Делается вывод о необходимости в рамках межкультурного общения при нахождении в ситуации безмолвия понимать противоречия в русском национальном характере, уважать различия, что будет способствовать полноценной коммуникации между представителями разных культур.

Ключевые слова: молчание, невербальное общение, культура, русская литература, межкультурное общение.

ях между людьми, а не за крайности. В межличностном общении русских наблюдаются два противоречащих друг другу стиля поведения: молчание и многоречивость возможны в коммуникации с одним и тем же человеком. Поскольку все представители нации способны на такое противоречивое поведение, необходимо выявить глубинные причины такого явления.

Цель статьи - анализ молчания как особенности невербального поведения русского народа, отражённой в его языке, литературе, культуре.

В толковом словаре русского языка под редакцией Д.Н. Ушакова говорится, что молчание - 'состояние молчащего человека; безмолвие, отсутствие речи, разговора; отсутствие звуков, тишина' [7]. В словаре Т.Ф. Ефремовой молчание объясняется как 'процесс действия по глаголу молчать; результат такого действия; отсутствие голосов, звуков, звуковых сигналов; полная тишина' [2]. В переносном смысле слово означает 'отсутствие публичных высказываний о чём-либо; отсутствие публикаций в какой-либо период времени (у писателя, ученого, журналиста и т. п.); отсутствие писем, вестей и иных сведений о себе' [Там же]. Определение молчания в китайской интернет-энциклопедии Baidu следующее: 'не говорить, молчать, не любить разговаривать' [11]. Словарь современного китайского языка объясняет молчание с помо- 
щью характеристик 'не любить говорить и смеяться' и 'не говорить [6]. Хотя есть различия в конкретных значениях, все данные определения включают в себя ключевую информацию о том, что в состоянии молчания не говорят и что это состояние временное. Молчание может продолжаться несколько коротких секунд или несколько длинных и эмоционально сложных минут, пока один из участников общения не ответит на вопрос или не перейдёт к новой теме, тем самым нарушив тишину и завершив состояние молчания.

И китайские, и российские ученые изучают состояние молчания. Российские ученые в большинстве случаев интегрируют при этом лингвистику, психологию, философию и другие дисциплины и по-разному, на основе различных исследовательских подходов, анализируют молчание. Китайские ученые обычно сосредоточиваются на анализе молчания в тесной связи с человеком и обществом.

Н.Д. Арутюнова называет молчание «отрицательным феноменом» [1, с. 417], не обладающим собственной значимостью, смысл которому «придаёт контекст, ситуация, регламент социального поведения, поверья, ритуал» [Там же, с. 418]. С.В. Меликян делит «молчание» на две категории: с одной стороны, выделяется молчание говорящего, с другой - молчание слушателя. Молчание говорящего выполняет медитативную, риторическую, терминационную, выжидательную, эмотивную, аттрактивную функции и функцию эмоциональной замены вербального общения; молчание слушателя также выполняет медитативную и терминационную функции, а также функции отказа от контакта и функции эмоциональной оценки и сомнения, которые связаны с негативным отношением слушателя к говорящему. С.В. Меликян уточняет функцию молчания с точки зрения эмоциональной ориентации и конкретных деталей, раскрывая внутренние эмоции обеих сторон в общении [5, с. 46-51].

Н.Б. Корнилова делит молчание на «женское молчание» и «мужское молчание» в зависимости от пола, а затем делит «женское молчание» на «вынужденное молчание» и «поверхностное молчание» [3, с. 182]. Первое связано с подчиненным статусом женщин в обществе, с тем, что мужчины находятся у власти и доминируют над женщинами, а второе является результатом компромисса или борьбы, которая ведётся в такой социальной среде. В общественных местах, где много мужчин, женщины в определенной степени лишены права говорить, выражать свою мысль, и они обычно используют «принудительное» молчание, чтобы поддерживать гармонию и порядок в такой ситуации [Там же, с. 184]. По словам китайского ученого Чжоу Миньцюань, поверхностное молчание «как коммуникативная стратегия женщин» не только показывает чувство наполненности словами и смыслом, но также отражает нежность и деликатность женщин [9, с. 30].

«Молчание» является важным понятием в русской литературе. Рассмотрим стихотворение Ф.И. Тютчева «Silentium!»:

Молчи, скрывайся и таи

И чувства и мечты свои -

Пускай в душевной глубине

Встают и заходят оне

Безмолвно, как звезды в ночи, -

Любуйся ими - и молчи.

Как сердцу высказать себя?

Другому как понять тебя?

Поймет ли он, чем ты живешь?

Мысль изреченная есть ложь.

Взрывая, возмутишь ключи, -

Питайся ими - и молчи.

Лишь жить в себе самом умей -

Есть целый мир в душе твоей

Таинственно-волшебных дум;

Их оглушит наружный шум,

Дневные разгонят лучи, -

Внимай их пенью - и молчи!.. (1829).

Название этого стихотворения - «Silentium» - на латинском языке обозначает 'тишина'. Стихотворение состоит из трёх строф, каждая из которых заканчивается словом «молчи». Состояние молчания передаётся в стихотворении словами и сочетаниями: «в душевной глубине», «заходят», «безмолвно», «внимай». Создаётся впечатление, что ранее лирический герой стремился излить свои чувства, «высказать себя», хотел, чтобы другие поняли его мысли. Однако теперь он понял, что его собственные мысли не могут быть поняты другими и не могут быть переданы другому человеку. Даже если мысль выражена, переносимая языком, она становится «ложью», как только произнесена, поэтому лучше вернуться в зону молчания.

Рассмотрим отрывок из рассказа Л.Н. Андреева «Молчание»:

- И мне... - сухой голос дрогнул, точно в нем что переломилось, - и мне, думаешь, легко? Как будто не вижу я, что поедает тебя какое-то горе... а какое? И я, твой отеи, не знаю его. Разве должно так быть?

...

С этого дня о. Игнатий перестал говорить с дочерью, но она словно не замечала этого. По-прежнему она то лежала у себя в комнате, то ходила и часто-часто вытирала ладонями рук глаза, как будто они были у нее засорены.

И, сдавленная двумя этими молчащими людьми, сама любившая шутку и смех, попадья робела и терялась, не зная, что говорить и что делать.

Герой рассказа, священник, якобы невзначай зашел в комнату дочери и заметил её вялость, душевное смятение и слабое состояние здоровья. Он не мог не беспокоиться за неё, но выразить своё волнение мог только словами. Но дочь ответила на тревогу отца молчанием. Священник размышлял о холодном и неумолимом Петербурге, который отнял у дочери живость, но как отец 
он был беспомощен к такой ситуации. Молчание стало не лучшим выходом из ситуации: постепенно в этой безмолвной атмосфере отвращение и неприязнь священника к городу превратились в ненависть к дочери. Со временем молчание затронуло и жену священника, и всю семью окутало ужасное безмолвие.

Молчание священника было обусловлено его понимаем отцовского достоинства: он не знал, как заботиться о дочери, и ничего не знал о том, что случилось с нею в Петербурге. Возникло противоречие между авторитетом отца и отцовской любовью. Слова озабоченности со временем стали проявлением мужского шовинизма. Молчание дочери - это обреченный на провал ответ на ситуацию. Интересно, что молчание матери напоминает болезнь, которой она заразилась от других членов семьи.

Рассмотрим истоки противоречивого понимания молчания в русской культуре. Во-первых, необходимо обратить внимание на систему ценностей.

На огромной территории России смешиваются и развиваются восточная и западная культуры, при этом большинство современных россиян больше подвержены влиянию Запада и его ценностей. Долгий период крепостного права, западная либеральная и демократическая атмосфера, принесенная русскими западниками, выступления русских корифеев литературы против темной системы прошлого - всё это придало исторический вес молчанию... Правда, эти события ушли в прошлое, но наложили глубокий отпечаток на россиян, заставив их обратиться в сторону Запада, восхищаться его свободой и безудержностью, стремиться обрести больше прав.

При этом некоторые люди в обществе и сегодня находятся под сильным влиянием восточной мысли, с её общинностью и соборностью. Община, образованная кровными узами и имущественными отношениями, гарантирует стабильную жизнь людей. Община - это весь их мир. Основные и второстепенные жизненные события происходят в относительно закрытой деревне, и все личные действия подчиняются коллективному. У жителей села ослаблено личностное мышление, им нужно только следовать решениям коллектива и избегать экстраординарных поступков. В таких условиях люди со временем теряют способность выражать свои суждения, и даже если у них есть демократическое право на свободное выражение мнения, для жителей общины более ценно их невидимое рабство. Этот образ мышления, складывавшийся в течение веков, проник в современное общество и унаследован последующими поколениями: в современной социальной среде так же не любят выражать свои взгляды, следуют за лидером, не любят бороться и дебатировать, склонны к гармонии и единообразию.

Вторым фактором, воздействовавшим на русское молчание как культурное явление, стало вероисповедание.

После крещения в 988 году Россия приняла право- славную веру как священную и использовала догматы православия для регулирования поведения народа. Аскетизм закрепился в русской православной вере с конца XV по XVI века. Его вдохновителем был монах Нил Сорский, который выступал против владения церковью землей и имуществом, а также ратовал за то, чтобы монахи держались подальше от соблазна денег и мирских проблем, жили в бедности, стремились к собственному духовному богатству, а не к внешнему великолепию и материальному достатку. Нил Сорский со своими учениками практиковал медитацию на болоте вдали от монастыря.

Хотя подвижникам во главе с Нилом Сорским не удалось широко распространить аскетизм, в конце концов другие верующие всё же приняли некоторые их идеи. До сих в русской культуре распространено представление о том, что христиане будут благословлены Богом только в том случае, если будут умеренным в своих желаниях и станут вести тяжёлую отшельническую жизнь. Поэтому для русского народа приемлемо молчание как один из признаков аскетизма, умеренности (в данном случае в речи). Такое молчание не является бездействием или молчаливым терпением: это своего рода проявление храбрости и настойчивости. В то же время для современных россиян собственные интересы становятся более важными, и созерцательное молчание постепенно утрачивает своё значение, поскольку может привести к потере множества выгод.

Третий фактор, под влиянием которого формируется русское молчание, - гуманистическая среда.

Среда, которая складывается в культуре народа в разные исторические периоды его существования, имеет разную степень воздействия на психологию людей и её проявления - молчание, депрессию и др. Гуманистическая среда оказывает незримое, но мощное влияние на невербальное поведение людей, в том числе на такое явление, как молчание. Несомненно, люди действуют в соответствии с особенностями эпохи, а гуманистическая среда иногда побуждает их выражать себя и раскрепощать свой разум, а иногда - отвечать на происходящее молчанием отдельных людей и даже всего общества.

Февральская революция, произошедшая в России в 1917 году, завершилась свержением монархии; в результате Октябрьской революции был установлен социализм, а социальная атмосфера стала относительно либеральной и демократической. Затем Россия пережила ряд значимых событий, таких как сталинские репрессии, хрущевский XX съезд Коммунистической партии СССР, реформы М.С. Горбачева и установление нового мышления. Советский Союз распался в 1991 году, и советский флаг с серпом и молотом ушёл в прошлое. Конец эпохи всегда означает начало новой неизвестной эпохи. Интеграция различных идей, их столкновение служат тому, что российское общество становится не полностью восточным или западным, а имеющим как восточные, так и западные характеристики. В период серьезных потрясе- 
ний актуальным становится вопрос о том, куда должна идти Россия, и множество исторических событий заставляли россиян неоднократно переосмыслить ответ на этот вопрос.

Иногда в стране создаются условия для того, чтобы свободно высказывать свое мнение вслух, определяя прогресс национального развития страны, а иногда в силу давления всего общества людям предпочтительнее молчать, опасаясь неприятностей. Порой молчание может быть единственным способом ответа на событие, как это происходило во время Великой Отечественной войны, «давшей примеры героического молчания партизан под пытками» [4, с. 34]. Поэтому неудивительно, что у россиян двойственное отношение к молчанию.

И, наконец, четвёртый фактор - природный. Россия это страна с огромной территорией и множеством лесов. Цао Вэйань описывает впечатления от леса, который может воздействовать на эмоции людей: «Сонная тишина в лесу пугает людей. Мрачный и тихий шум с верхушек старых деревьев кажется зловещим предзнаменованием, которое может привести к формированию мистицизма у россиян» [8, с. 4-5]. В ряде регионов России часто бывают плохие погодные условия, в результате чего люди вынуждены жить относительно закрыто и далеко от других людей. Живущим здесь приходится сражаться с природой в одиночку, полагаясь на собственные силы в решении проблем и попытках преобразования природы. В долгие и холодные зимы размышления о будущем человека, семьи и страны становятся темой вечернего чаепития. Постепенно, в бесконечных размышлениях, люди все больше внимания обращают на внутреннюю ценность тишины и предпочитают оставаться вдали от шума и суеты. Молчание имеет отклик в духовном мире людей, живущих в отрыве от цивилизации.

В то же время многие россияне проживают сейчас в относительно процветающих городах. Экономические, культурные и политические атрибуты города заставляют их активно интегрироваться в сообщество, участвовать в социальной деятельности, обретать новое «я» в социальном взаимодействии. В глазах многих горожан молчание - это признак отказа от общения, что для большинства живущих здесь неприемлемо.

Итак, в характере русского человека есть очевидная двойственность, которая проявляется в культуре молчания. Русские охотно выступают за свободу и стремятся пользоваться своими гражданскими правами, однако долгая история самодержавия ограничивает их свободолюбие. Для них сложен принцип «золотой середины»: они либо за, либо против, сопротивляются или уступают. Нейтральное отношение и равнодушие не те варианты, которые приемлемы для русской культуры. Под влиянием восточной и западной культуры, в связи с традиционными православными верованиями, под воздействием уникальной гуманистической и природной среды у русского народа сформировалась особая культура молчания, в большинстве случаев выступающего как позитивное явление. Следовательно, молчание в общении с русскими нельзя игнорировать, но нет необходимости и переоценивать его. В межкультурном общении необходимо принимать молчание русского человека, но в то же время можно показывать дружеское, искреннее отношение, демонстрировать уважение культурных различий.

\section{ЛИТЕРАТУРА}

1. Арутюнова, Н.Д. Феномен молчания / Н.Д. Арутюнова // Язык о языке / Под общ. ред. Н.Д. Арутюновой. - М.: Языки русской культуры, 2000. - С. $417-436$.

2. Ефремова, Т.Ф. Новый толково-словообразовательный словарь русского языка / Т.Ф. Ефремова. - М.: Дрофа, 2000. - 1233 с. (онлайн версия) [Электронный ресурс]. - URL: http://www.classes.ru/all-russian/russian-dictionary-Efremova.htm (дата обращения: 17.04.2021).

3. Корнилова, Н.Б. Молчание влюбленных (краткий анализ смысловых лакун) / Н.Б. Корнилова // Вопросы психолингвистики. - 2006. - № 3. - С. 182-186.

4. Крылова, М.Н. «Молчит как партизан». Прецедентные сравнения из сферы истории / М.Н. Крылова // Русская речь. - 2017. - № 6. - С. 31-35.

5. Меликян, С.В. Молчание в русском общении / С.В. Меликян // Русское и финское коммуникативное поведение: Сборник. Вып. 1. - Воронеж: Изд-во ВГТУ, 2000. - C. 46-51.

6. Словарь современного китайского языка [Электронный ресурc]. - URL: https://www.zdic.net (дата обращения: 17.04.2021).

7. Толковый словарь русского языка: В 4 т. / Под ред. Д.Н. Ушакова. - М.: Астрель, АCT, 2000 [Электронный ресурc]. - URL: http://feb-web.ru/feb/ushakov/ ush-abc/default.asp (дата обращения: 05.04.2021).

8. ЦЦао Вэйань. Новое рассуждение о истории России: основные вопросы, влияющие на развитие истории России / Цао Bэйань. - Пекин: China Social Sciences Press, 2002. $-397 \mathrm{C}$.

9. Чжоу Миньцюань. Молчание: исследование по гендерной лингвистике / Чжоу Миньцюань // Журнал университета иностранных языков Н0А. - 2012. № 4. - C. 29-34.

10. Эпштейн, М.Н. Слово и молчание в русской культуре / М.Н. Эпштейн // Звезда. - 2005. - №10. - С. 202-222.

11. Baidu [Электронный ресурс]. - Режим доступа: URL: https://baike.baidu.com (дата обращения: 05.04.2021).

(c) Тан Цзяминь (tangjm2020@|zu.edu.cn). 